\title{
Transforming water management in Llanelli, UK
}

1 Christopher Ellis BEng, MSC Water Engineer, Arup, Cardiff, UK

2 Rosemary Cripps BSC Water Engineer, Arup, Cardiff, UK
3 Michelle Russ ACMI

RainScape Regulation Manager, DŴr Cymru Welsh Water, Newport, UK

4 Simon Broom BEng, CEng, CEnv, FICE, MInstLM Senior Engineering Manager, Morgan Sindall, Newport, UK
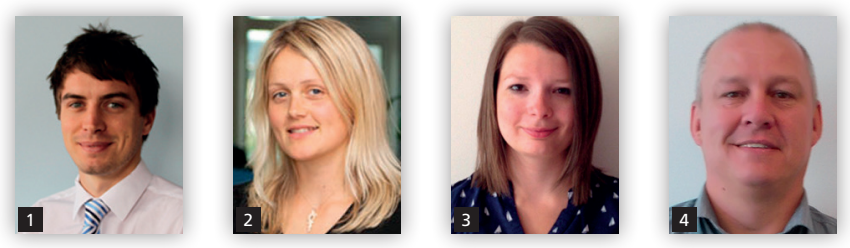

In Llanelli, South Wales, high volumes of surface water have led to excess discharges from combined sewer overflows into designated shellfish waters and the risk of widespread property flooding. A comprehensive catchment-wide modelling assessment was undertaken to develop a pioneering, community-focused strategy based on retrofitting sustainable drainage systems. This paper outlines the approach taken to develop and compare catchment strategy options; describes the journey through delivery and performance evaluation; and explores the social, environmental and economic constraints and opportunities. The project is a blueprint for integrated catchment management and water-sensitive urban design, promoting best practice in flooding mitigation and climate-change resilience across the UK.

\section{Introduction}

Sewerage infrastructure in the UK traditionally consists of combined networks whereby foul and surface water are mixed and conveyed to wastewater treatment works. This method of flow and treatment originates from the Victorian era, and the infrastructure was sized accordingly. In recent times, however, urbanisation has led to a considerable increase in impermeable area, increasing demand beyond the original design capacity. In many urban areas this is causing flooding and pollution-related issues.

Llanelli, a town situated on the northern coastline of the Loughor Estuary in South Wales, demonstrates a common UK issue associated with combined sewer networks. The population of Llanelli increased by $6 \cdot 3 \%$ between 2001 and 2011 (ONS, 2011), and is projected to rise by a further $15 \cdot 2 \%$ before 2036 (Welsh Government, 2011). Furthermore, the impacts of climate change are predicted to increase the frequency and intensity of rainfall, putting additional strain on an already overloaded network.

Traditionally, combined sewer overflows have been added to sewer networks to protect public health by reducing sewer flood risk which has resulted from population growth, urban creep and infiltration. A combined sewer overflow typically consists of a dryweather flow channel, with a restriction placed on pass-forward flow by means of an appropriately sized downstream pipe or flow control device. Diluted combined sewage that exceeds this passforward flow during rainfall flows over a weir and is screened before discharging to a watercourse. There are approximately 30000 combined sewer overflows in the UK, many of which were constructed during times of limited design guidance or without due assessment of environmental impact.

Llanelli consists of five main sub-catchments, each serviced by a series of sewage pumping stations which feed into Llanelli's wastewater treatment works. A total of 29 main combined sewer overflows located strategically around the catchment reduce flood risk, eventually discharging to the Loughor Estuary, which includes two designated shellfish waters - Burry Inlet North and South. Some of these combined sewer overflows were found to discharge frequently, in one case up to 140 times annually; collectively discharging around 3.76 million $\mathrm{m}^{3}$ annually into the environment.

There were 115 properties known to be at risk of sewer flooding in the Llanelli catchment as a result of excess surface water entering the public sewer network. This has left little scope for additional much-needed growth. The town's employment rate is below the Welsh average, and $12 \%$ of areas in the town fall in the $10 \%$ most deprived in Wales (NAW, 2010). With no intervention, these problems are set to worsen, stifling the town's development as infrastructure becomes unable to cater for future investment. The flooding issues are not isolated to Llanelli; it is predicted that $3 \cdot 2$ million people in the UK will be at risk of flooding from similar urban drainage issues by 2050 (Houston et al., 2011).

The primary driver for this project was to limit the frequency and volume of combined sewer overflow discharges to sensitive water bodies. In achieving this, the strategy also sets out to alleviate flooding caused by hydraulic overload of the sewer network, while making the town more resilient to climate change. 
Since 2007, Dŵr Cymru Welsh Water has been developing its approach to sustainably managing the amount of surface water entering the public sewer network. The strategy draws on a number of well-established techniques, such as sustainable drainage systems and water-sensitive urban design, and has been as 'RainScape'. It seeks to address surface water issues at root cause rather than storing flows further down in the catchment.

In 2010 Welsh Water committed to developing the strategy to sustainably address the drivers in Llanelli. Reducing the amount of surface water entering the sewer network would reduce the number of combined sewer overflow discharges in the catchment, tackle sewer flooding issues in the area and also make the network more resilient to climate change.

The success of the Llanelli strategy lies predominantly within five elements of strategy development, each of which are continually being reviewed and advanced through a cycle incorporating key components (see Figure 1). Two strategy options were initially investigated through this process: a traditional storage solution and a suite of individual intervention schemes based on the RainScape initiative.

\section{Data collection and modelling}

Understanding how an existing sewer system operates is fundamental to developing appropriate and effective solutions. In 2010 an extensive data-collection exercise was commissioned. Data were pooled from key stakeholders through monthly workshops, subsequently verified and bolstered by site survey and flow-monitoring data. Knowledge sharing between Welsh Water, Carmarthenshire County Council, Natural Resources Wales and the Welsh government resulted in comprehensive catchment understanding.

Data collection was carried out in parallel with a model build exercise undertaken using Infoworks Collection Systems software. Geographic information system asset data and ground model data were used to generate a 'base model', which was then refined with

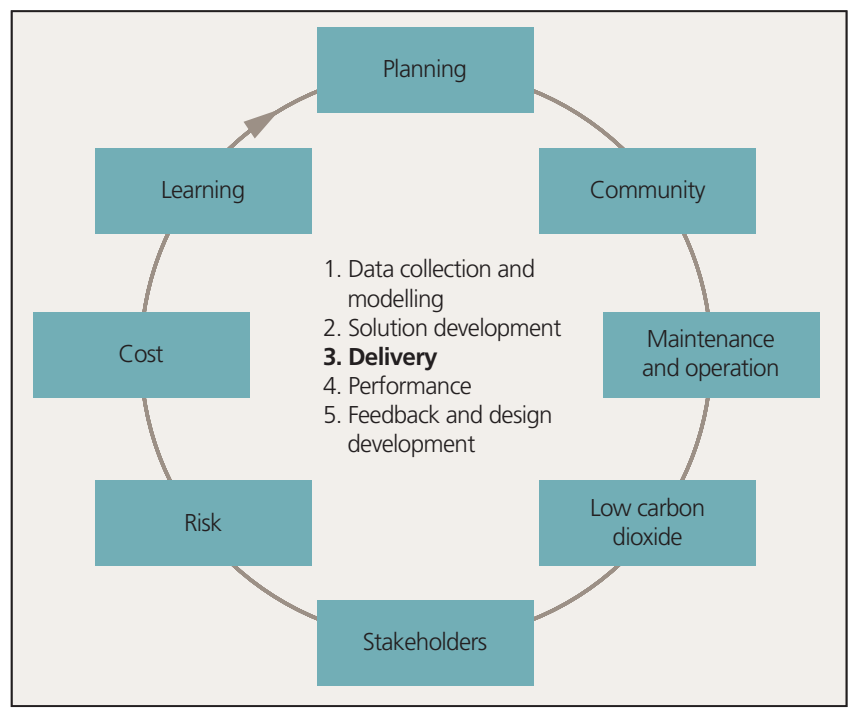

Figure 1. Model showing the cyclical process adopted to implement the long-term strategy in Llanelli (courtesy Arup) survey information and as-built data. The model was verified for dry weather and storm events using sewer flooding records and combined sewer overflow discharge data, along with short-term detailed flow surveys consisting of 308 flow monitors in place for an 8 week period. A long-term flow survey of 50 flow monitors in place for 6 months was used to assess seasonal variation in infiltration and base flow and highlighted a variation in base flow of $250 \%$ between summer and winter months. River-level gauges were placed in local watercourses to assess sewer-river interactions, during which several direct river inflows were also located.

During solution development a key requirement of the model was to replicate the impact of retrofitting sustainable drainage systems and the removal of surface water from the combined sewer. The model therefore needed accurately to reflect impermeable areas and infiltration throughout the catchment. To achieve this, targeted impermeable area surveys were undertaken and supplemented by flexible flow surveys that tracked inflow and infiltration within the sewer network. Network maps were also used to highlight potential surface water connections, areas of potential mass infiltration and large steep sewers capable of conveying excessive flows within the sewer network. The result of the process was a calibrated model which accurately reflected observed combined sewer overflow discharge counts as well as flooding. It reflected the large impermeable rainfall response of the Llanelli catchment and the tendency of the network to exhibit long drain-down periods after prolonged wet periods.

The outputs of combined sewer overflow discharge frequencies, durations and volumes from the hydraulic model were transferred to a coastal dispersion model to assess the relative impact of discharges from each combined sewer overflow on the Loughor Estuary. This modelling and evaluation exercise, carried out by Intertek, helped identify key contributors to shellfish water quality exceedance and later informed the development of targeted solutions.

\section{Solution development}

Traditional strategies for reducing combined sewer overflow discharges and sewer flood risk in urban catchments include providing hard infrastructure, such as storage tanks, and increasing the capacity of pipes and treatment works to manage excess flows. This method of water management can be appealing as it is a recognised technology to water companies, operators and environmental bodies with easily quantifiable results. However, there can be associated risks: future development, the onset of climate change and urban creep can significantly reduce the effectiveness of the storage and the interventions can lead to increased operating costs, especially in pumped catchments such as Llanelli.

As an alternative to hard engineering techniques, non-traditional solutions were developed centred on the use of sustainable drainage systems techniques in conjunction with asset optimisation. While sustainable drainage systems technology is tried and tested on new developments in the UK, the concept of retrofitting schemes into urban settings is relatively new. An element of this approach, incorporating 'green infrastructure' as storm-water management, presented an opportunity to integrate multiple social and environmental benefits within local communities.

A range of targeted traditional and non-traditional solutions were subjected to a multi-criteria analysis to assess potential benefit against cost (see Figure 2). Additional criteria such as embodied 
carbon dioxide and society benefit were assessed up front and used to rank options. When compared with traditional solutions, the retrofitting of sustainable drainage systems to many areas in Llanelli was shown to be the most effective means to overcome the issues associated with network capacity.

It was demonstrated that traditional solutions alone were not an affordable or effective means of delivering the initial target for reduction in combined sewer overflow discharges and flood risk. In total, $269000 \mathrm{~m}^{3}$ of storage volume would be needed for the Llanelli catchment, costing $£ 377$ million. This storage volume, while hypothetically providing a reduction in combined sewer overflow discharges, relies on tanks emptying between storms. Within a catchment such as Llanelli, where the sewer network exhibits exceptionally long drain-down times, it was clear that storage alone could not offer this assurance. In addition the complex treatment processes at Llanelli wastewater treatment works (which is designed to denitrify, remove phosphorus and disinfect final effluent) cannot operate reliably with the range and variability of biological load implied if such large tanks were to operate.

Adopting a non-traditional surface-water-management approach will have a much lower capital cost of $£ 98$ million to deliver the same initial target reduction in combined sewer overflow discharges and flooding within the Llanelli catchment. Sustainable drainage schemes, such as the use of green infrastructure, could also offer community benefits absent from traditional engineering solutions. In addition, the solutions are resilient; green infrastructure matures to become more effective at removing surface water and additional green infrastructure can be incorporated over time to deliver additional flow removal when it is needed.

The final strategy was developed collaboratively with scheme partners and key stakeholders. As a result of the multi-criteria analysis, and through various risk and value exercises, an innovative, non-traditional approach was agreed. The adopted strategy consists of a number of individual schemes prioritised based on the results of the multi-criteria analysis. Welsh Water has committed $£ 26$ million towards the delivery of a selection of these schemes in Llanelli by 2020 .

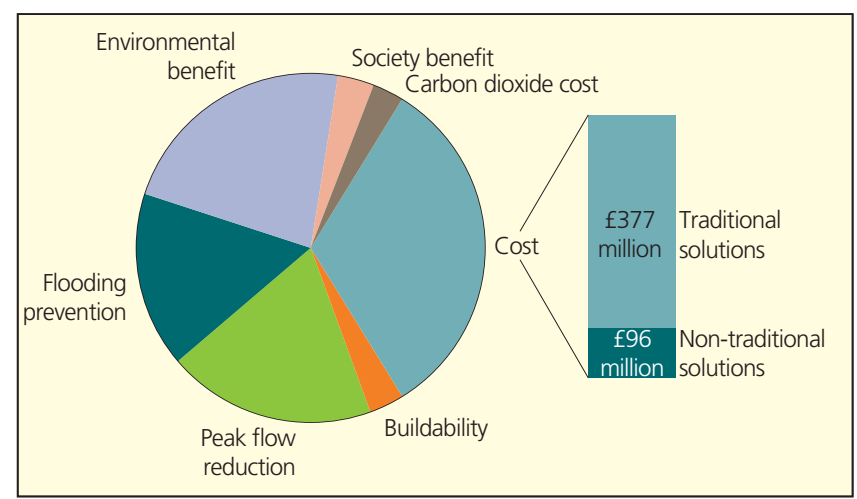

Figure 2. Pie chart showing the criteria and weighting used in developing the strategy to compare traditional and non-traditional engineering solutions, and subsequently to prioritise individual solutions in the resulting strategy (courtesy Arup)

\section{Delivery}

The strategy being implemented in Llanelli involves maximising the use and efficiency of existing assets while implementing a range of strategically located retrofitted surface-water-management schemes to manage surface water sustainably at source. To date, ten schemes have been constructed within the Llanelli catchment (see Figure 3).

\subsection{Objectives}

Defining targets for individual schemes involved building upon existing data captured during the modelling phase. A detailed model of each of the sites was calibrated and verified with flow and depth survey data and was tested using a series of designed rainfall events generated using the Flood Estimation Handbook (CEH, 1999). Green infrastructure solutions were then added and optimised to best manage peak flows, maximise volume removal and provide the greatest benefit in terms of flood alleviation and combined sewer overflow discharge reduction. Some of the key hydraulic design requirements for the systems, developed through evaluation of hydraulic modelling predictions and related design codes in parallel with key stakeholder requirements, included the following

- retaining levels of service within highway drainage

- emptying within $24 \mathrm{~h}$ following rainfall

- aim to attenuate a 1 in 5 year event

- attenuate a minimum of $5 \mathrm{~mm}$ rainfall

- prevent property flooding during a 1 in 30 year event

- manage exceedance events greater than 1 in 30 .

\subsection{Methodology}

Intercepting surface water run-off and directing it into new planted elements is integral to the green infrastructure schemes. A flow-reduction target specific to each of the schemes dictated the hydraulic characteristics of each green infrastructure element. These elements were subsequently shaped around the multiple social, environmental and economic opportunities and constraints present in varying degrees at different sites across the catchment. Early contractor involvement was fundamental to the design process, with a close working relationship between Welsh Water (client), Morgan Sindall (contractor) and Arup (designer), leading to a set of solutions that were buildable, maintainable and affordable.

Innovative basins and planters use specially selected soils, plants and trees to slow the flow while improving water quality and encouraging evapotranspiration. The placement of these bespoke attenuation units has been carefully considered to complement and enhance the existing local built environment, the desire being to provide wider community benefits which go beyond flood alleviation through incorporating open green spaces, improving local air quality, encouraging local biodiversity enhancement and promoting health and well-being.

Traditional drainage solutions are often hidden from the public, resulting in a limited understanding of how they function and perform and how they interact with the natural and built environment. Creating visible features to capture rain water not only provides watermanagement benefits, but improves public understanding, involvement and the sense of ownership when communicated effectively. 


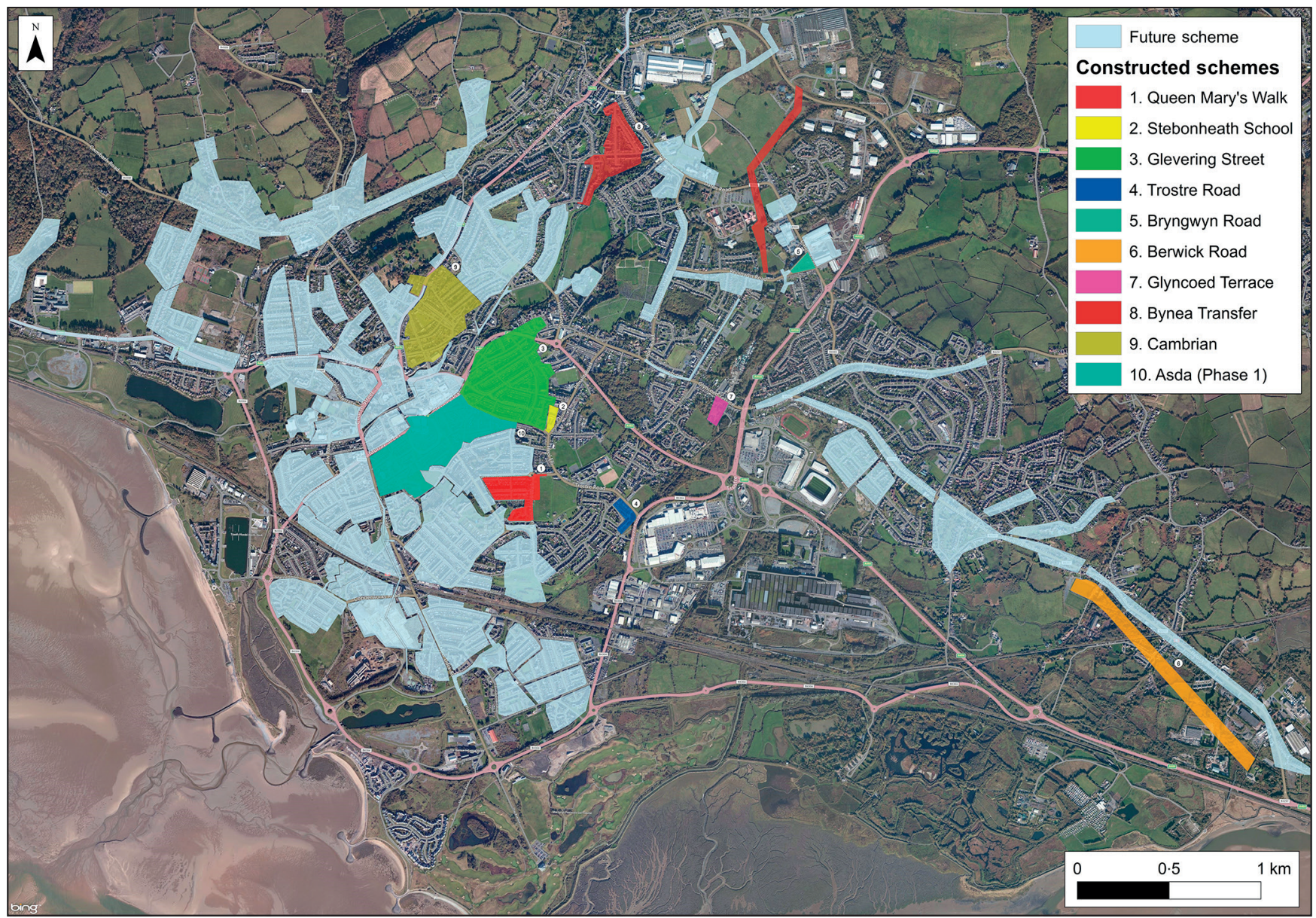

Figure 3. Map of Llanelli showing location of the ten priority schemes constructed between 2010 and 2015, plus possible future schemes to be completed as part of the long-term strategy for Llanelli (courtesy Arup, Ordnance Survey mapping courtesy Welsh Water, map copyright 2015 Her Majesty's Stationery Office, licence number WU298565)

\subsection{Case study - Glevering Street}

The Glevering Street scheme showcases many of the constraints and opportunities present within the Llanelli catchment (see Figure 4). The scheme involves the retrofitting of green infrastructure into several highly urbanised streets where existing surface water entered a combined sewer system. Peak flows in excess of $800 \mathrm{l} / \mathrm{s}$ from this area during a 1 in 5 annual exceedance probability event were a major contributor to sewage discharges, and seven properties in the immediate vicinity of this scheme were on Welsh Water's definitive flood list. The construction of this scheme was part funded by the European Regional Development Fund via Welsh Government due to the volume of highway runoff entering the public sewer network.

The design principle adopted at Glevering Street is based on the conveyance of surface water using overland routing and kerb drainage; directing run-off towards a network of roadside basins and planters. This network incorporates a range of products, many of which have been adapted to form innovative water-management systems. Collectively these are capable of reducing peak storm flows by $330 \mathrm{l} / \mathrm{s}$ ( 1 in 5 annual exceedance probability).

Trees present a major opportunity to generate multiple benefits. In Llanelli they are being used as landscape and ecological features as well as for surface-water management (see Figure 5). The design of tree root cell systems has been adapted to facilitate storm-water attenuation while also maximising the health of the tree. This has involved revising standard tree installation details from suppliers, incorporating improved soil drainage, soil specifications and appropriate tree and planting species (see Figure 6). The tree pits contain a high sand content (up to $70 \%$ by weight) to facilitate drainage while providing a preferable void ratio ( $20 \%$ by volume) for attenuation of flows. Many studies have suggested that trees can significantly improve soil permeability and infiltration rates (Skorobogatov et al., 2013). Post-construction results support these suggestions; the roadside tree planters are performing as intended through all four seasons and continue to improve as the trees and plants mature.

Planters incorporating trees have been constructed where constraints, such as space, dictate. Where non-tree planters 
Civil Engineering

Volume 169 Issue CE1
Transforming water management in Llanelli, UK Ellis, Cripps, Russ and Broom are spatially constrained, geocellular storage has been used to supplement the storage volume provided at the surface (see Figure 7). Geocellular storage of this form provides a lightweight structure of $95 \%$ void volume, allowing attenuation potential to be maximised while limiting geometry requirements at the surface (see Figure 8). Flows that enter the planter percolate through the soil media and granular layer before entering a series of belowground cells. During larger events flow can bypass the planter and fill the below-ground cells by way of an overflow gully. A vortex flow-control or similar flow-control device is used to ensure a limit is set on flow returned back into the sewer network.

Where space is less constrained, larger basins have been used to showcase water management, typically using existing free

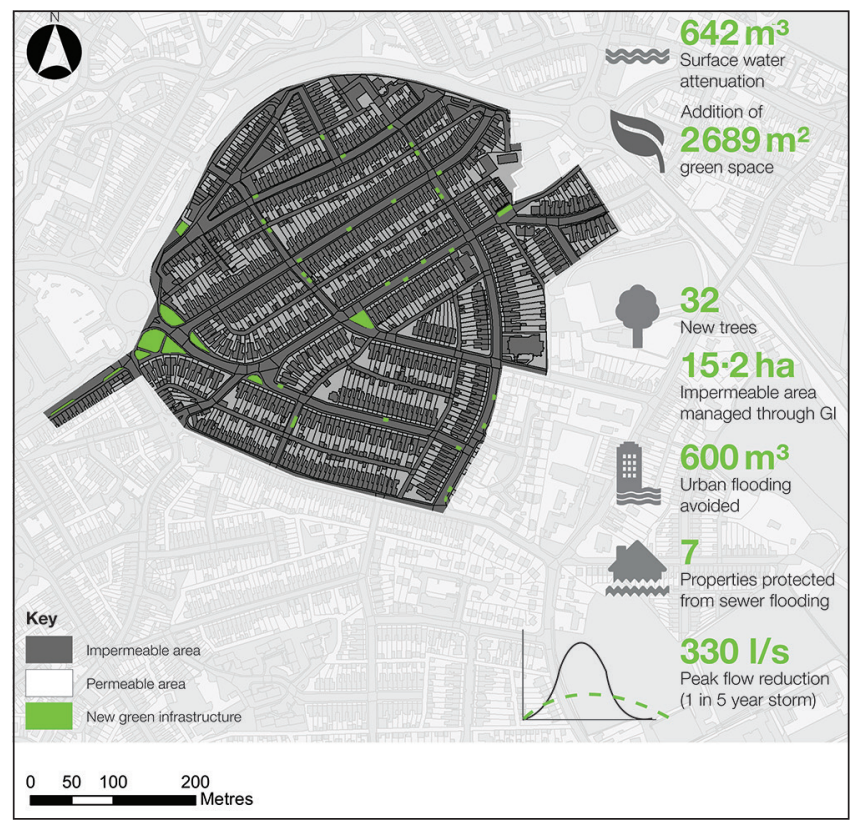

Figure 4. Benefits of the Glevering Street scheme, one of the early green infrastructure schemes now constructed as part of the Llanelli strategy (courtesy Arup, map courtesy Bing Maps, copyright 2010 Microsoft Corporation and data suppliers) space at road junctions and improving road safety. Gradients have been used to create features, whereby, through the use of weirs and channels, the flow of water becomes visible from separated pedestrian areas (see Figure 9). While demonstrating the principle

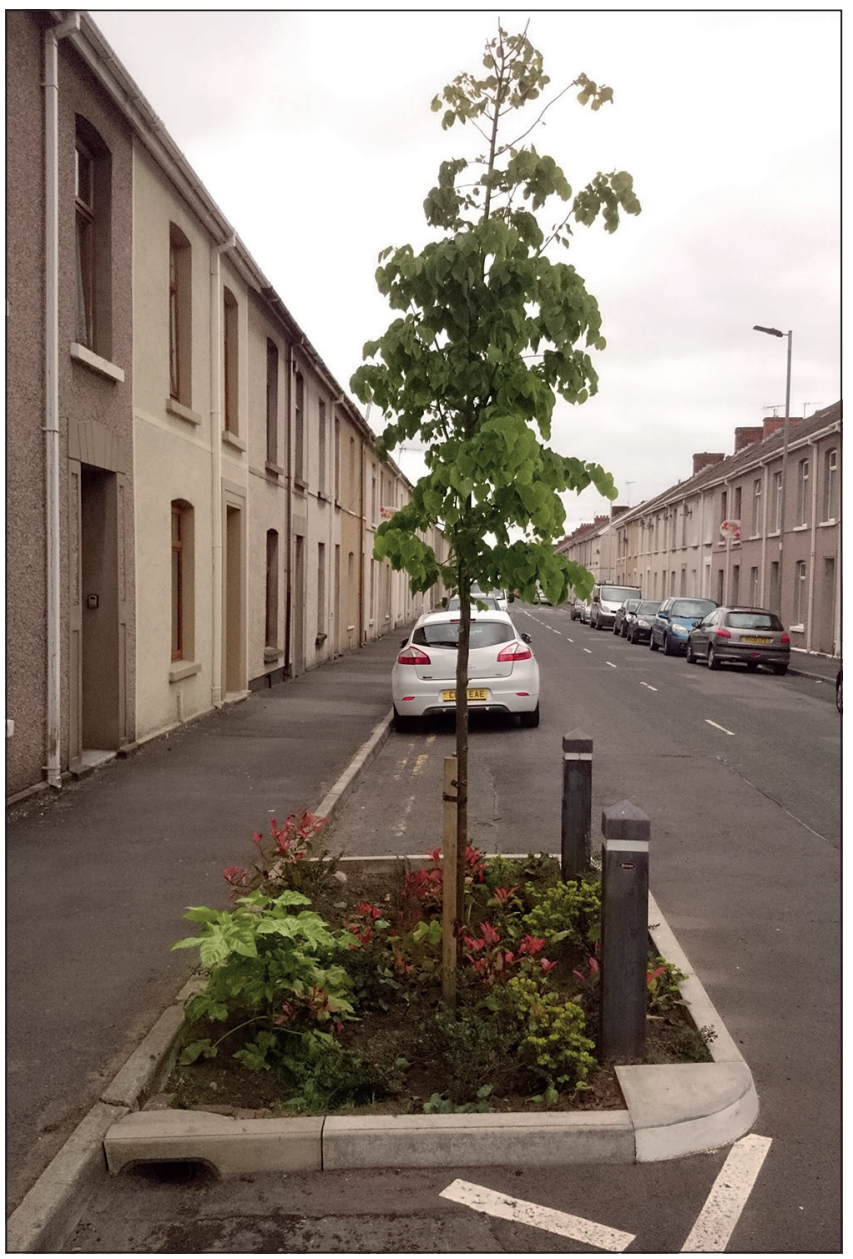

Figure 5. New urban tree constructed as part of the Glevering Street scheme to manage surface water (courtesy Welsh Water)

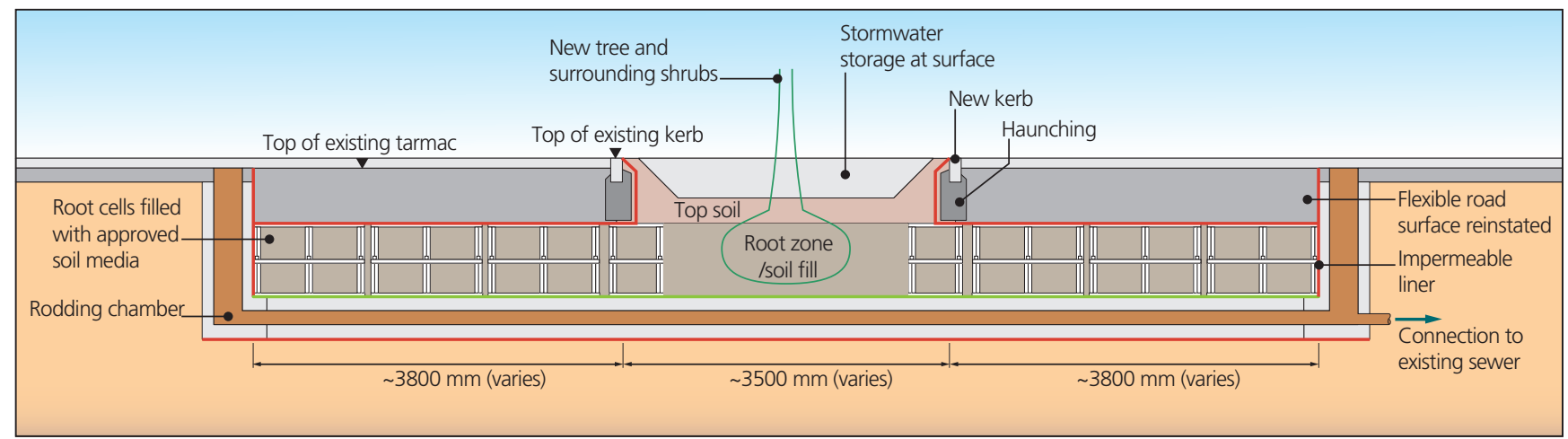

Figure 6. Construction detail for urban trees in Glevering Street. The image is adapted from a construction drawing (courtesy Arup and Welsh Water) 
of water management, the separation and cascading effect creates a treatment train whereby sedimentation and settlement take place, followed by a gradual improvement in water quality as flow travels through vegetation and soil media.

\subsection{Challenges}

Many of the challenges faced in Llanelli can be attributed to the relative infancy of retrofitting green infrastructure in the UK. Limited design guidance and few example schemes have resulted in a learning process which continues to evolve and develop. New ways of thinking can present new risks. The risk-management approach adopted has been pivotal to the success of this strategy thus far. In working for a common goal, all parties have taken ownership of risk and mitigation, and when confronted with challenges have worked collectively to resolve them.

Adoption can be a critical barrier for many sustainable drainage systems projects with cost, long-term responsibility and maintenance often the three key obstacles. These are being overcome in Llanelli on a scheme-specific basis. Many of the schemes involve the modification to existing highway assets, such as Glevering Street, and are being maintained in the short term by

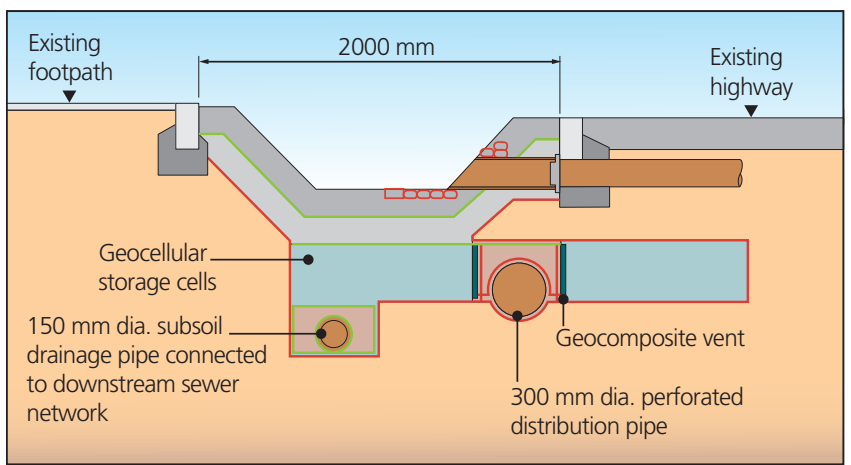

Figure 7. Construction detail for a roadside planter in Glevering Street. The image is adapted from a construction drawing (courtesy Arup and Welsh Water)

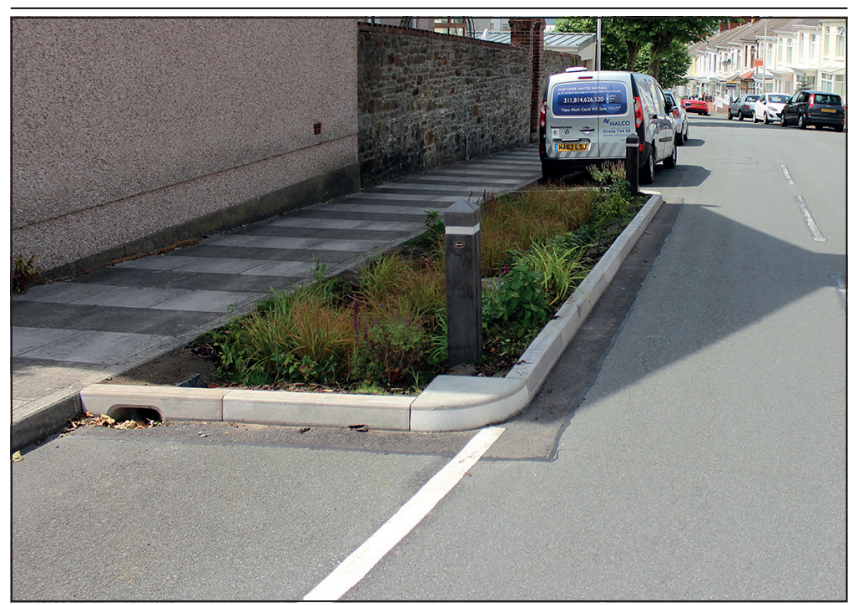

Figure 8. New roadside planter with storage cells constructed as part of the Glevering Street scheme to manage surface water (courtesy Welsh Water)
Welsh Water through the contractor as part of an agreed maintenance period, with assets being adopted as part of the highway drainage network by Carmarthenshire County Council. This agreement to adopt the assets has resulted from a close working relationship from the project inception stage. Discussions and agreements started up front during the overall strategy development, and progressed into the construction phase. Incorporating industry-recognised details into the green infrastructure elements, such as standard gully units in easily accessible locations, provides the adopter with an asset that is maintainable alongside the existing, traditional infrastructure. Scheme-specific maintenance schedules have been drawn up to ensure that the assets are properly maintained to guarantee the long-term operation of the system.

A major design constraint across Llanelli is limited potential for flows to be infiltrated into the ground and underlying bedrock. This is a result of historical mining activities, contamination and the presence of a clay-rich glacial till within the vicinity of many of the schemes. To mitigate the risk of local subsidence and contaminant mobilisation, an impermeable liner, such as a geosynthetic clay liner, has been used where geotechnical investigations have highlighted poor ground conditions. To allow each of the elements to fully drain, a sub-surface perforated drain is used, preventing the systems from becoming frequently waterlogged.

A common challenge encountered in retrofitting sustainable drainage systems into an urban environment is the presence of existing below-ground infrastructure. Utility plans provided by statutory undertakers offer approximate locations of major infrastructure; however, undertaking large-scale surveys to accurately distinguish location, condition and depth often proves heavily disruptive and uneconomical. In Llanelli, a balance was struck in locating elements in less 'utility heavy' areas, carrying out surveys at key locations while building a degree of flexibility in design; allowing for significant on-site modifications to suit local conditions where required. These factors were especially important in dense urban areas such as Glevering Street, where the close proximity of residential properties resulted in a network of major utilities and service laterals (see Figure 10). In this instance, agreements were reached with regard to easements or diversion of major utilities prior to construction. Agreements regarding minor utilities and service

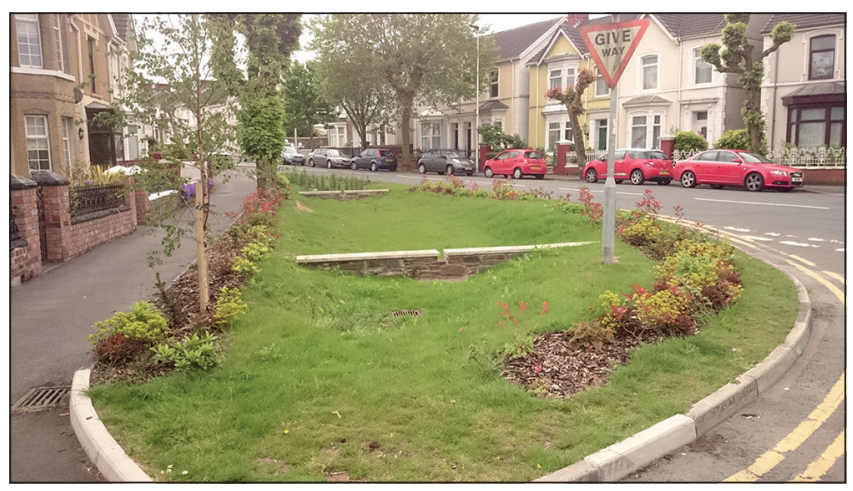

Figure 9. New bio-retention basin constructed as part of the Glevering Street scheme to manage surface water, showing the use of a weir to provide a cascading water feature while dividing the basin to form a treatment train (courtesy Welsh Water) 


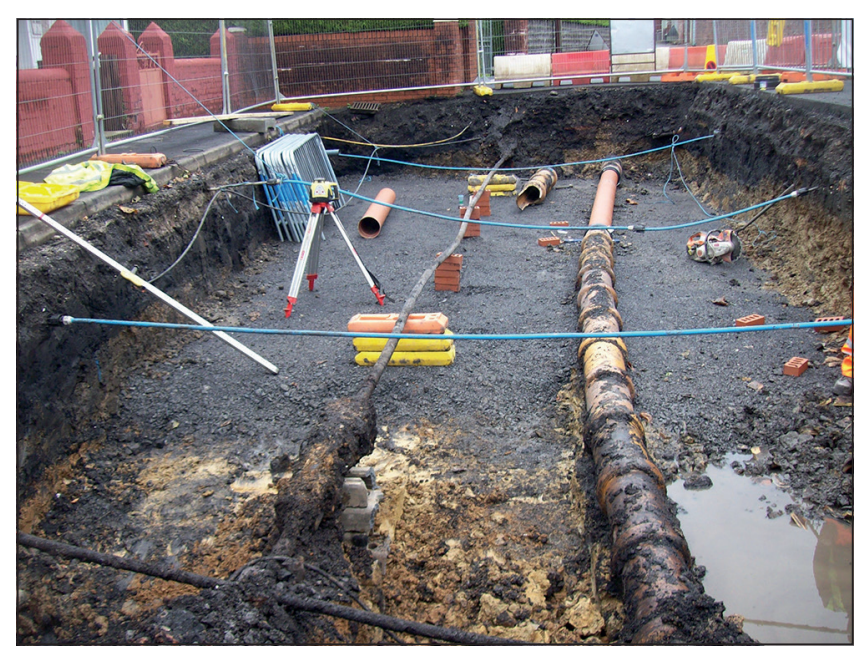

Figure 10. Utilities encountered during the construction of a roadside planter with storage cells in Glevering Street - while key utilities were picked up during an initial site survey, the presence of additional utilities and laterals present a construction challenge (courtesy of Welsh Water)

laterals were often made on site, with easements and diversions agreed with the utility provider on a case-by-case basis.

The experience of the contractor in working with local authorities and private utility companies played an important role in overcoming challenges posed on site. While working with Welsh Water offered improved ability to work around existing clean- and wastewater assets, keeping other service providers informed of construction programme and the interface of green infrastructure with their assets has helped to speed up the construction process and reduce the risk of lengthy delays. The contractor undertook monthly meetings with Carmarthenshire County Council and utility providers. This allowed other programmed construction work within the highway to take place simultaneously, providing benefit to all parties involved while also minimising disruption to the local community.

Community engagement has formed a vital role in the success of scheme implementation in Llanelli. Keeping the local community informed from an early stage allowed concerns with the design to be addressed more easily, but also provided the community with an insight into the importance of sustainable water management. The success of community engagement was well demonstrated through implementing a green infrastructure scheme within a local school, whereby students contributed directly towards the design.

Welsh Water led on the communication of the works in Llanelli and used a number of methods to contact their customers and also to address any concerns throughout the design and construction of the schemes, and beyond. Some of the activities undertaken include

- direct liaison with around 3000 customers

- six public exhibitions and four drop-in sessions

- 11500 letters and newsletters sent out

- 35 home visits to customers

- 1500 doors knocked on
- responding to over 100 customer letters and emails

- opening an information station in the town centre.

Welsh Water will be undertaking a customer feedback exercise to understand how customers feel about the scheme postconstruction, and how the features constructed have been accepted by the community.

Welsh Water has also managed the relationships with a plethora of political stakeholders in the area, including town councillors, county councillors, assembly members and members of parliament. By keeping these prominent figures in the community informed of scheme progression, expectations have been managed and complaints minimised.

Another key element to ensuring community buy-in was the facilitation group that had been set up to share information and discuss issues with the local authority. Chaired by Welsh Water, the group has provided a platform whereby local knowledge of issues has been shared, including in relation to traffic management, and has also developed a partnership relationship across multiple organisations and multiple disciplines. As a result of this group, the local authority has invaluably supported scheme development and delivery, and has also agreed to relax parking restrictions to minimise disruption to residents.

A challenge faced in the design of this scheme, recognised through engagement with the local community, was the potential loss of parking caused by roadside green infrastructure. The solution was to place the planters and basins strategically in locations less frequently used for parking, such as side streets, re-engineered junctions and in areas with existing parking restrictions in place.

As with the design phase, the delivery of each of the green infrastructure schemes has involved a close working relationship between the client, the contractor and the designer. Lessons learned from all schemes are being fed back into the planning and design phases of subsequent schemes.

Delivering these solutions in an existing urban community differs significantly from the delivery of traditional drainage techniques. Due to the complex nature of the construction works and potential for disruption to customers, programmes have been phased accordingly.

Streamlining the construction process has involved the design and construction team working closely with the supply chain. In combination with an informative, customer-focused approach from the contractor's site teams this has resulted in quicker and less disruptive installations - a process that is again being refined in a feedback loop.

Some key lessons have been learnt in Llanelli in relation to landscaping. The selection of appropriate soil mixes, shrubs and planting affects the long-term appearance, performance and maintenance of green infrastructure. Managing public expectation with regard to the planting selection and appearance of freshly planted areas is important and now forms a key part of public engagement. Furthermore, in response to public feedback, planting selections are now focused on providing seasonal interest and yearround structure with the use of evergreen plants.

The quality and density of planting was carefully considered during the design stage. Ensuring this attention to detail is reflected on site requires a close working relationship between designers and the landscape contractor with regard to implementing the design to specification, the selection of plants and trees and ongoing maintenance. 
Transforming water management in Llanelli, UK

Ellis, Cripps, Russ and Broom

\section{Performance}

The hydraulic benefit of each of the schemes continues to be assessed through flow and depth monitoring. These data, downloaded on a weekly basis by the contractor, are fed back into verified hydraulic models to compare the betterment brought about during recorded storm events pre- and post-construction. The results thus far have shown excellent performance of each of the initial sustainable drainage systems schemes during 2013/2014's wettest winter on record (Met Office, 2014).

The impact of the retrofitted green infrastructure elements on peak flow reduction, which is summarised in Table 1 , is well demonstrated by the Queen Mary's Walk bioswale (see Figure 11). Here, during a 1 in 1 annual exceedance probability event, design phase model predictions indicated a $62 \%$ flow reduction would be achieved given the volume of attenuation provided. Postconstruction monitoring indicates an additional $25 \%$ reduction in peak flow has been achieved during some storms (see Figure 12). Similar observations are being made at other sites including Glevering Street and Stebonheath School.

The green infrastructure elements in Llanelli, through the natural processes of interception, evaporation and evapotranspiration are making a significant contribution with regard to flow reduction. The schemes at Queen Mary's Walk and Stebonheath School alone are removing $13250 \mathrm{~m}^{3}$ of surface water from the combined sewer network annually, drastically reducing sewer flooding incidents and minimising discharges from combined sewer overflows while also providing an operational cost benefit to Welsh Water.

As individual schemes are completed, a quantifiable benefit to the combined sewer network is realised by way of fewer combined sewer overflow discharges. Hydraulic modelling has initially been used to assess this benefit, with rain gauge data used to compare before and after discharge-frequency scenarios over the previous investment period (see Figure 13). This shows that with the investment of $£ 15$ million in Llanelli between 2010 and 2015 there is a reduction in annual combined sewer overflow discharge frequencies of up to $39 \%$

\begin{tabular}{|c|c|c|}
\hline Scheme name & $\begin{array}{l}\text { Peak flow } \\
\text { reduction: I/s ( } 1 \text { in } 5 \\
\text { annual exceedance } \\
\text { probability) }\end{array}$ & $\begin{array}{l}\text { Number of } \\
\text { properties } \\
\text { protected from } \\
\text { sewer flooding }\end{array}$ \\
\hline Queen Mary's Walk & 125 & Highway \\
\hline Stebonheath School & 53 & 0 \\
\hline Glevering Street ${ }^{\mathrm{b}}$ & $329^{a}$ & 7 \\
\hline Trostre Road ${ }^{b}$ & 26 & 10 \\
\hline Bryngwyn Road & 12 & 5 \\
\hline Berwick Road & 22 & 18 \\
\hline Glyncoed Terrace & 26 & 6 \\
\hline Bynea transfer & $192^{\mathrm{a}}$ & Highway \\
\hline Cambrian & $524^{a}$ & 0 \\
\hline $\begin{array}{l}\text { Asda (phase 1) including } \\
\text { Pottery Street }{ }^{b}\end{array}$ & $88^{a}$ & 10 \\
\hline \multicolumn{3}{|c|}{$\begin{array}{l}\text { a Target flow reduction } \\
\text { b The construction of this scheme part funded by the European Regional } \\
\text { Development Fund via Welsh Government }\end{array}$} \\
\hline
\end{tabular}

Table 1. Summary of benefits of constructed schemes in Llanelli
(St Michaels Church combined sewer overflow). Further to this, Welsh Water is working closely with Natural Resources Wales to establish a target operating frequency for combined sewer overflows by the end of the current investment period (2015-2020) that will improve shellfish water quality and help deliver Water Framework Directive (EC, 2000) improvements in the area.

Data collected over an 18 month period since the commissioning of the Queen Mary's Walk bioswale, used in combination with hydraulic modelling, are indicating that, as green infrastructure systems mature their ability to manage surface water improves (see Figure 14). While maintenance forms a key role in ensuring these green infrastructure assets continue to function into the future, hard engineering solutions such as storage tanks have more defined life cycles, and their ability to manage surface water generally deteriorates over time, from effects such as the onset of infiltration.

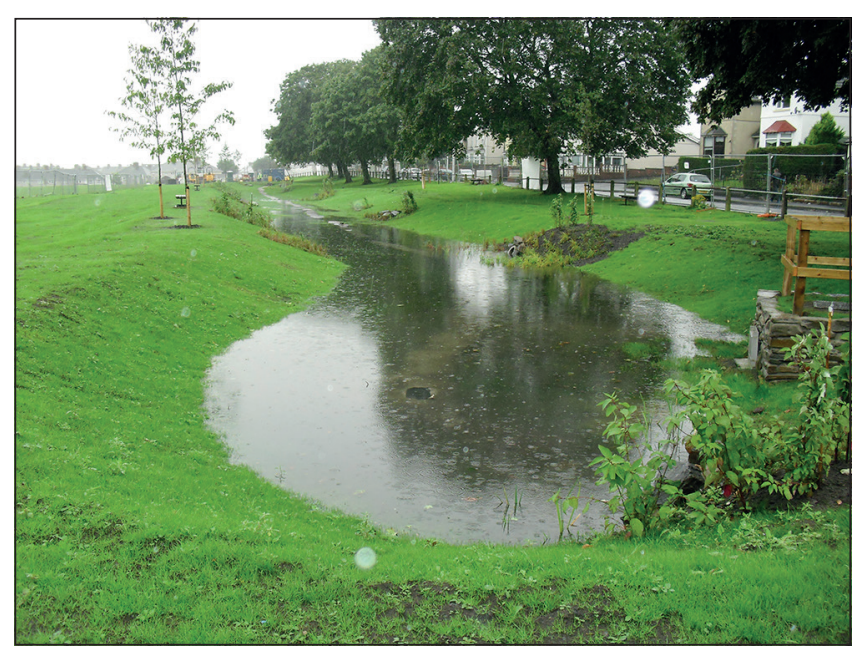

Figure 11. Queen Mary's Walk bioswale during operation - another priority scheme that has been constructed in Llanelli (courtesy Welsh Water)

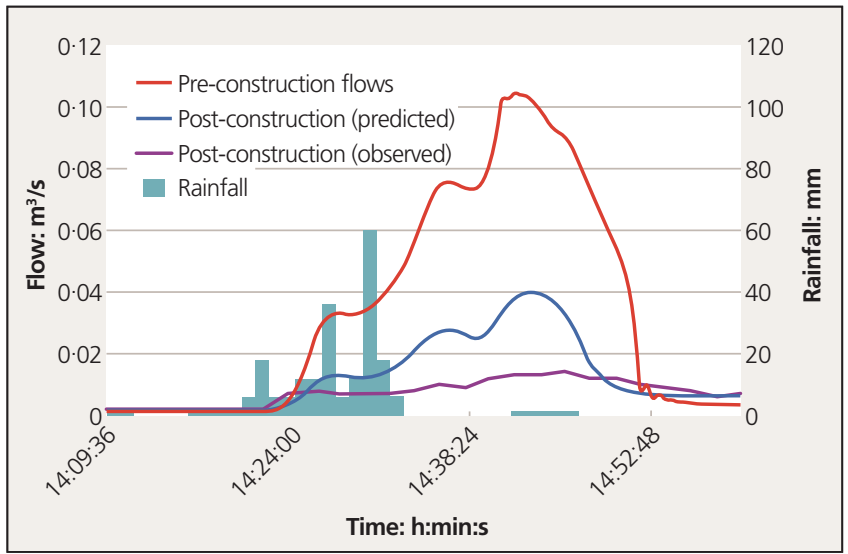

Figure 12. Flow reduction achieved from Queen Mary's Walk compared with predicted design flow reduction, based on results of a calibrated hydraulic model using rain gauge data and flow monitoring data (courtesy Arup and Welsh Water) 


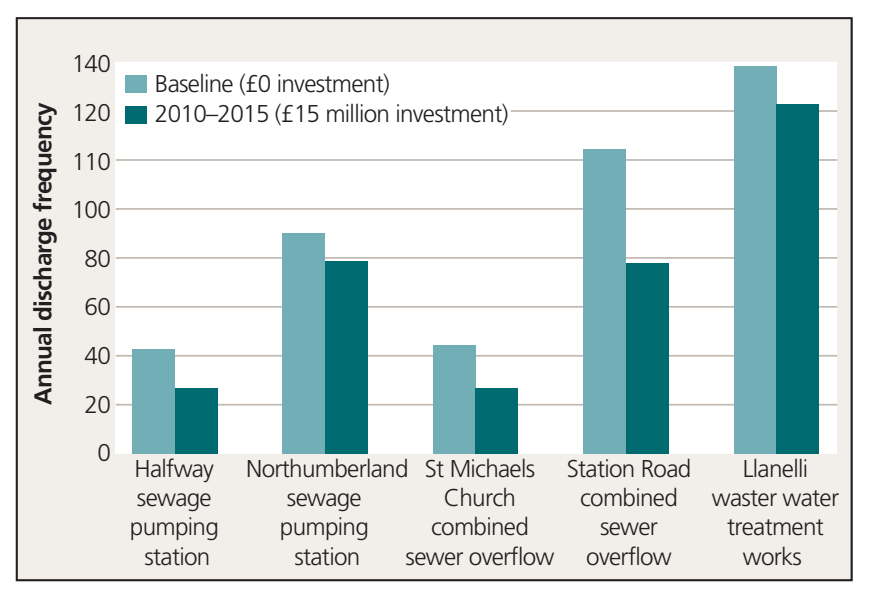

Figure 13. Predicted annual discharge frequencies for key combined sewage overflows over the previous strategy investment period (courtesy Arup and Welsh Water)

\section{Conclusions}

Catchment-wide hydraulic modelling and detailed solution design in the Welsh town of Llanelli has resulted in an innovative retrofit sustainable drainage systems strategy. Developed alongside Welsh Water's RainScape initiative, the strategy is reducing combined sewer overflow discharges and flood risk resulting from common UK issues relating to ageing and overwhelmed sewer networks. The pioneering approach not only provides a capital cost saving when compared with traditional hard engineering solutions, but green infrastructure schemes delivered as part of the strategy provide a range of environmental and social benefits.

Although the concepts behind sustainable drainage systems design are not complex, delivering a strategy on this scale has encountered challenges, particularly with regard to green infrastructure. These schemes are visible, in the public realm and impact upon the local community; hence planning and constructing them involves engaging with multiple stakeholders while satisfying a broad set of aspirations. Construction within an existing urban environment presents logistical challenges in dealing with existing infrastructure, public services and businesses. In many cases these challenges are being overcome through extensive planning and communication, with the lessons learnt at each stage of strategy being fed back into the development and planning of subsequent schemes.

The strategy demonstrates that the retrofitting of sustainable drainage systems in the form of green infrastructure can achieve considerable flow reductions which have surpassed expectations. While many of the systems constructed in Llanelli cannot use preferable green infrastructure processes, such as infiltration into the underlying ground, natural water management linked to the addition of trees and planting is actively preventing water from entering the sewer network. Furthermore, as these green elements mature, their ability to intercept surface water improves.

The complex task of retrofitting green infrastructure and other sustainable drainage systems technology in the centre of Llanelli is helping to regenerate historically deprived areas. While freeing up capacity within the sewer network is providing a platform for new housing and business development, the presence of green

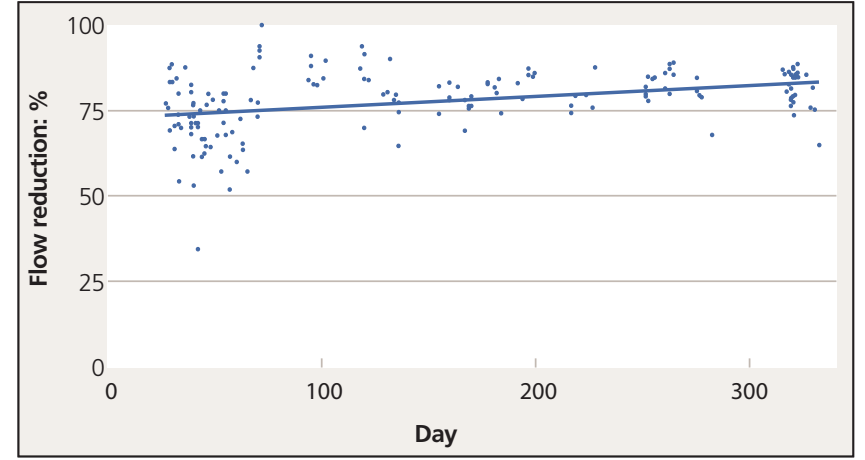

Figure 14. Flow reduction achieved during recorded storm events in 2014 at Queen Mary's Walk - a linear line of best fit plot suggests the new green infrastructure element is improving with time (courtesy Arup and Welsh Water)

infrastructure is improving the appeal of the town and acting as an engagement and education opportunity.

The catchment-wide strategy to manage surface water is the first of this scale in the UK. The successful implementation of early schemes has drawn attention from many stakeholders throughout the UK and abroad. In addition, lessons learned and results are helping to shape new design guidance and drive a more integrated approach to sustainable infrastructure. The authors believe that the steps made in Llanelli will encourage a new way of thinking to make towns and cities better, more resilient places.

\section{Acknowledgements}

The authors would like to thank their colleagues at Welsh Water, Morgan Sindall and Arup for the information and support they have provided for this paper.

\section{References}

CEH (Centre for Ecology \& Hydrology) (1999) Flood Estimation Handbook Centre for Ecology \& Hydrology, Wallingford, UK.

EC (European Community) (2000) Directive 2000/60/EC of the European Parliament and of the Council of 23 October establishing a framework for Community action in the field of water policy. Official Journal of the European Communities L327/1

Houston D, Werritty A, Bassett D et al. (2011) Pluvial (Rain-related) Flooding in Urban Areas: the Invisible Hazard. Joseph Rowntree Foundation, York, UK.

Met Office (2014) Wettest Winter for England and Wales Since 1766. Met Office, Exeter, UK. See http://www.metoffice.gov.uk/news/releases/ archive/2014/early-winter-stats (accessed 10/04/2015).

NAW (National Assembly for Wales) (2010) Key Statistics for Llanelli May 2010. National Assembly for Wales, Cardiff, UK.

ONS (Office for National Statistics) (2011) 2011 Census. Office for National Statistics, Newport, UK.

Skorobogatov A, Thorne W and Amell B (2013) Biological elements in rain garden design. Proceedings of the 2013 International Low Impact Development Symposium, St Paul, MN, USA.

Welsh Government (2011) Variant 2011-based Local Authority Population Projections for Wales, 2011 to 2036. Welsh Goverment, Cardiff, UK. See https://statswales.wales.gov.uk/Catalogue/Population-and-Migration/ Population/Projections/Local-Authority/2011-Based/PopulationProjectionsby-LocalAuthority-Variant-Year (accessed 16/11/2015). 